\title{
PELATIHAN PENGAMBILAN KEPUTUSAN BISNIS PLAN PENGEMBANGAN USAHA BERBANTUAN KOMPUTER BAGI PERCETAKAN SKALA KECIL DI TANGERANG SELATAN
}

\author{
Mochamad Yunus Fitriady ${ }^{1}$, Ponadi ${ }^{2}$ \\ ${ }^{1 \& 2}$ Jurusan Teknik Grafika, Politeknik Negeri Media Kreatif Jakarta \\ Jalan Srengseh Sawah, Jagakarsa, Jakarta Selatan 12640 \\ email: ${ }^{1}$ yunusfitriady@gmail.com; ${ }^{2}$ ponadi1234@gmail.com
}

\begin{abstract}
ABSTRAK
Bisnis plan atau perencanaan usaha sangat penting bagi wirausaha dalam memulai maupun mengembangkan bisnis seorang wirausaha, jika rencana usaha tersebut dibuat secara irasional, tidak cepat dan tepat sasaran, maka diduga kuat dalam pelaksanaan usahanya akan tertinggal bahkan gagal dalam persaingan bisnis yang semakin kompleks pada era MEA saat ini.

Khalayak sasaran/mitra kegiatan Program Kemitraan Masyarakat (PKM) adalah merupakan wirausaha percetakan berskala kecil, yaitu: mitra ke-1 CV. Eka Mulia Jati Production (EMJ Production) merupakan perusahaan yang bergerak di bidang percetakan, alamat perusahaan di jalan W.R. Supratman No.40 Cempaka Putih, Ciputat Timur, Tangerang Selatan, sedangkan mitra ke-2 adalah UD. Alief Jaya Finishing yang berdomisili di Jalan Mawar No. 9, Ciputat, Tangerang Selatan.

Permasalahan mitra yang bersifat urgent yang harus diberikan solusinya adalah: 1). Khalayak sasaran/mitra dalam pembuatan bisnis plan sebagian besar dalam penilaian maupun pengambilan keputusannya secara irasional. 2). Khalayak sasaran/mitra tidak dapat membuat bisnis plan pengembangan usaha secara rasional, efektif dan efisien. dan 3). Khalayak sasaran/mitra belum menerapkan bantuan komputer, program descriptive statistic dan penyajian tabel menggunakan program microsoft office excel minimal tahun 2007 sebagai alat bantu pengambilan keputusan bisnis plan pengembangan usaha.

Metode pendekatan dan penyelesaian yang akan dilakukan adalah upaya pemberian solusi yang ditawarkan dengan beberapa metode, yaitu: 1). Urun rembug, yaitu: pertemuan bernuansa kekeluargaan untuk memahami secara rinci kondisi, kebutuhan dan potensi mitra. 2). Dikusi terarah (Focused Group Discussion-FGD) untuk memberikan pemahaman kepada mitra tentang orientasi solusi yang diberikan. 3). Pelatihan: kegiatan pembelajaran untuk meningkatan pengetahuan, pemahaman, dan keterampilan pemanfaatan descriptive statistic dan tabel menggunakan program excel sebagai alat manajemen dalam rangka penilaian untuk pengambilan keputusan rasional pada bisnis plan 4). Jangka waktu: 8 bulan masa pelatihan. pembelajaran, pembinaan, pendampingan, pembimbingan maupun praktek, evaluasi dan review hingga mitra dapat megumpulkan, mengolah, dan membuat penyajian data baik secara tabel dan descriptive statistic pada program excel minimal tahun 2007, sebagai dasar pengambilan keputusan bisnis plan pengembangan usaha yang berdampak berdampak kepada peningkatan pendapatan bisnis dan daya saing produk.
\end{abstract}

Melalui kegiatan Program Kemitraan Masyarakat ini luaran/keluaran yang diharapkan, adalah khalayak sasaran/mitra dapat membuat bisnis plan pengembangan usaha secara rasional, efektif dan efisien.

Keyword : Pelatihan, Pengambilan Keputusan, Bisnis Plan, Pengembangan Usaha, Berbantuan Komputer

\section{PENDAHULUAN}

Sejak tanggal 1 Januari 2015 dimana telah dimulainya AEC singkatan dari Asean Economic Community atau yang lebih dikenal Masyarakat Ekonomi ASEAN (MEA) menjadikan industri-industri yang ada di Indonesia mendapatkan tantangan yang semakin tinggi. Begitu pula dengan industri percetakan di Indonesia, industri yang mengalami pertumbuhan hingga pada tahun 2015, dan pada saat dimulainya era MEA, sejak tanggal 1 Januari 2015 dan era gobal sampai dengan saat ini mendapatkan ancaman atau tantangan yang serupa, yaitu permasalahan 
yang ada di perusahaan, mulai dari keterbatasan Sumber Daya Manusia (SDM), akses ke sumber daya produktif, rendahnya kemampuan dalam riset, dan legalitas usaha, yang harus segera dibenahi agar perusahaan tersebut dapat bersaing dalam bisnis.

(http://www.depkop.go.id/content/read/kemenkop-

dorong-internasionalisasi-ukm-melalui-ekspor, Agus Muharam, 2016. diakses 18 Juni 2017)

Permasalahan tersebut tidak jauh berbeda yang dirasakan oleh khalayak sasaran/mitra kegiatan PKM, yaitu CV. Eka Mulia Jati Production dan UD. Alief Jaya Finishing, kedua perusahan mitra tersebut bergerak di bidang percetakan. Domisili kedua perusahaan tersebut di daerah Ciputat Tangerang Selatan. Berdasarkan survey, pengamatan dan hasil urun rembug/focus group discussion antara pengabdi dengan mitra menyimpulkan bahwa manajemen perusahan tidak dapat membuat bisnis plan dalam mengembangkan usahanya secara rasional, efektif, dan efisien, dan kedua mitra sepakat untuk mengikuti pelatihan pengambilan keputusan bisnis plan pengembangan usaha berbantuan komputer sebagai upaya penyelesaian permasalahan.

\section{Perumusan Masalah dan Identifikasi Permasalahan Mitra}

Berdasarkan latar belakang di atas, dapat dirumuskan permasalahan, bahwa, "Bagaimana perusahan dapat membuat bisnis plan dalam pengembangan usahanya secara rasional, efektif, dan efisien?", dari rumusan tersebut dapat diurai rincian permasalahan yang dapat diidentifikasi pada mitra adalah sebagai berikut :
a) Khalayak sasaran/ mitra dalam pembuatan bisnis plan sebagian besar dalam penilaian maupun pengambilan keputusannya secara irasional.
b) Khalayak sasaran/mitra tidak dapat membuat bisnis plan pengembangan usaha secara rasional, efektif dan efisien.

c) Khalayak sasaran/mitra belum menerapkan bantuan komputer, program descriptive statistic dan penyajian tabel menggunakan program microsoft office excel minimal tahun 2007 sebagai alat bantu penilaian dan pengambilan keputusan bisnis plan pengembangan usaha.

\section{HASIL DAN PEMBAHASAN}

\section{Kendala dan Capaian Luaran}

Kendala kegiatan PKM dengan judul "Pelatihan Pengambilan Keputusan Bisnis Plan Pengembangan Usaha Berbantuan Komputer Bagi Percetakan Skala Kecil di Tangerang Selatan", yakni: dana, energi, penyesuaian waktu, kualitas sumberdaya manusia serta kendala teknis maupun administrasi kegiatan baik dari pengabdi maupun mitra khalayak sasaran.

Adapun keberhasilan berdasarkan capaian luaran kegiatan Pengabdian masyarakat ini untuk lebih jelasnya dapat dilihat pada tabel dibawah ini.

Tabel 3.1

TARGET CAPAIAN LUARAN PKM 2018

\begin{tabular}{|c|c|c|}
\hline NO & JENIS LUARAN & $\begin{array}{l}\text { INDIKATOR } \\
\text { CAPAIAN }\end{array}$ \\
\hline \multicolumn{3}{|c|}{ LUARAN WAJIB } \\
\hline 1 & $\begin{array}{l}\text { Publikasi ilmiah pada Jurnal } \\
\text { ber ISSN/Prosiding }\end{array}$ & Accepted \\
\hline 2 & $\begin{array}{l}\text { Publikasi pada media masa } \\
\text { cetak/online/repocitory PT }\end{array}$ & Proses editing \\
\hline 3 & $\begin{array}{l}\text { Peningkatan daya saing } \\
\text { (peningkatan kualitas, } \\
\text { kuantitas, serta nilai tambah } \\
\text { barang, jasa, diversifikasi } \\
\text { produk, atau sumber daya } \\
\text { lainnya ) }\end{array}$ & $\begin{array}{c}\text { Besar } \\
\text { peningkatan }\end{array}$ \\
\hline 4 & $\begin{array}{l}\text { Peningkatan penerapan iptek } \\
\text { di masyarakat (mekanisasi, } \\
\text { IT, dan manajemen) }\end{array}$ & Penerapan \\
\hline 5 & $\begin{array}{l}\text { Perbaikan tata nilai } \\
\text { masyarakat (seni budaya, } \\
\text { sosial, politik, keamanan, } \\
\text { ketentraman, pendidikan, } \\
\text { kesehatan) }\end{array}$ & $\begin{array}{c}\text { Sudah } \\
\text { Dilaksanakan }\end{array}$ \\
\hline \multicolumn{3}{|c|}{ LUARAN TAMBAHAN } \\
\hline 1 & $\begin{array}{l}\text { Publikasi di jurnal } \\
\text { internasional }\end{array}$ & Draft \\
\hline 2 & $\begin{array}{l}\text { Jasa; rekayasa sosial, metode } \\
\text { atau sistem, produk/barang }\end{array}$ & Penerapan \\
\hline 3 & Inovasi baru TTG & Tidak Ada \\
\hline
\end{tabular}




\begin{tabular}{|r|l|c|}
\hline NO & \multicolumn{1}{|c|}{ JENIS LUARAN } & $\begin{array}{c}\text { INDIKATOR } \\
\text { CAPAIAN }\end{array}$ \\
\hline 4 & $\begin{array}{l}\text { Hak kekayaan intelektual } \\
\text { (Paten, Paten sederhana, Hak } \\
\text { Cipta, Merek dagang, } \\
\text { Rahasia dagang, Desain } \\
\text { Produk Industri, } \\
\text { Perlindungan Varietas } \\
\text { Tanaman, Perlindungan } \\
\text { Desain Topografi Sirkuit } \\
\text { Terpadu) }\end{array}$ & Tidak Ada \\
\hline 5 & Buku ber ISBN & Draft \\
\hline
\end{tabular}

dan pembahasan dalam kegiatan ini di paparkan secara parsial berdasarkan tempat masing-masing (objek kegiatan), yang kemudian disimpulkan gambarannya secara umum berdasarkan dari tujuan kegiatan ini.

\section{HASIL DAN PEMBAHASAN}

\section{Capaian Keberhasilan Kegiatan PKM}

Keberhasilan program dapat dilihat tercapai-tidaknya tujuan program kegiatan PKM tertuang dalam rencana kegiatan, capaian keberhasilan Kegiatan PKM merupakan capaian keberhasilan dalam rangka memberikan solusi permasalahan umum mitra yang urgent, yakni khalayak sasaran/mitra tidak dapat membuat bisnis plan pengembangan usaha secara rasional, efektif dan efisien, Sedangkan rincian permasalahan yang dapat diidentifikasi pada khalayak sasaran/mitra adalah sebagai berikut : a) Khalayak sasaran/mitra dalam pembuatan bisnis plan sebagian besar dalam penilaian maupun pengambilan keputusannya secara irasional. b) Khalayak sasaran/mitra tidak dapat membuat bisnis plan pengembangan usaha secara rasional, efektif dan efisien dan c) Khalayak sasaran/mitra belum menerapkan bantuan komputer, program descriptive statistic dan penyajian tabel menggunakan program microsoft office excel minimal tahun 2007 sebagai alat bantu penilaian dan pengambilan keputusan bisnis plan pengembangan usaha. Berikut tabel capaian keberhasilan kegiatan PKM per 29 Oktober 2018.

Dapat disimpulkan bahwa pencapaian keberhasilan program pengabdian pada tahun 2018 per tanggal 29 Oktober 2018 adalah sebesar 100\%, artinya permasalahan mitra/khalayak sasaran semua dapat diatasi.

Sedangkan capaian keberhasilan berdasarkan luaran kegiatan Pengabdian masyarakat berupa luaran wajib maupun luaran tambahan yang dibuat oleh pengabdi per tanggal 29 Oktober 2018, adalah sesuai dengan tabel 3.1 sebagai berikut:

Dari tabel diatas tersebut dapat disimpulkan bahwa pencapaian keberhasilan luaran kegiatan Pengabdian masyarakat berupa luaran wajib maupun luaran tambahan yang dibuat oleh pengabdi per tanggal 29 Oktober 2018 adalah luaran wajib sebesar 100\%, artinya luaran wajib sudah selesai outputnya, yang belum selesai yaitu menunggu terbit jurnal ber-ISSN dan terbitnya media online, begitu pula dengan luaran tambahan yang dibuat oleh pengabdi per tanggal 29 Oktober 2018 sebesar $100 \%$, yang belum selesai adalah finishing draft jurnal internasional dan proses fiinishing pembuatan buku ber-ISBN.

\section{Uraian Capaian Keberhasilan Kegiatan PKM}

Adapun uraian capaian keberhasilan kegiatan PKM, dari tahap persiapan, pelaksanaan sampai evaluasi adalah sebagai berikut:

\section{Keberhasilan Persiapan Kegiatan PKM}

Metode pendekatan dan penyelesaian yang dilakukan adalah upaya pemberian solusi yang sudah dilakukan dengan beberapa metode, yaitu: Urun rembug, yaitu: pertemuan bernuansa kekeluargaan untuk memahami secara rinci kondisi, kebutuhan dan potensi mitra.

Pada fase pesiapan mitra telah berpartisipasi dengan baik pada kegiatan dengan rinci sebagai berikut:

a. Menyiapkan PC ataupun laptop sebagai media pelatihan pemanfaatan bantuan komputer program descriptive statistic dan penyajian tabel menggunakan program microsoft office excel minimal tahun 2007 sebagai alat bantu pengambilan keputusan bisnis plan dan pengembangan usaha dengan baik 
b. Mitra menyiapkan data perusahaan, baik primer maupun sekunder, membantu mengumpulkan data yang dibutuhkan, menyajikan dan menganalisa data produksi dan penjualan rentang waktu 2 Minggu selama 4 Bulan (Juli, Agustus, September dan Oktober) Tahun 2018 dengan baik

Pada fase persiapan, pengabdi telah melakukan koordinasi dengan melakukan urun rembug dengan kedua mitra, yaitu pertemuan bernuansa kekeluargaan untuk memahami secara rinci kondisi, kebutuhan dan potensi kedua mitra. Urun rembug maupun pelatihan, bimbingan dan pembelajaran dilaksanakan oleh pengabdi bersama kedua mitra di Yayasan SufainyRava, yang beralamat di Jalan Nurul Huda No.72 RT.002/ RW.04, Kelurahan Cempaka Putih, Kecamatan Ciputat, Tangerang Selatan, Banten. Sedangkan pelaksanaan pembuatan bisnis plan/praktek dilaksanakan di CV. Eka Mulia Jaya Production

Pada tanggal 30 s.d. 31 Mei 2018 pada jam 8.00 s. d 16.00 WIB telah dilaksanakan kegiatan koordinasi awal kerjasama PKM, pengabdi telah melakukan koordinasi dalam rangka kegiatan pengabdian untuk mengetahui kondisi, kebutuhan dan potensi mitra, dan hasilnya adalah, mitra dalam keadaan siap mengikuti semua kegiatan pengabdi dari persiapan sampai evaluasi kegiatan serta penerapan, kegiatan pengabdi sangat dibutuhkan dalam rangka peningkatan pendapatan bisnis kedepan. Pada hari itu juga persiapan peserta, dan alat berupa komputer maupun laptop serta download data analysis pada program excel 2007 untuk kegiatan pengabdian disiapkan, sedangkan peserta maupun partisipan pada kegiatan pengabdian dengan judul "Pelatihan Pengambilan Keputusan Bisnis Plan Pengembangan Usaha Berbantuan Komputer Bagi Percetakan Skala Kecil di Tangerang Selatan", adalah sebanyak 14 orang peserta dari kedua mitra.

\section{Keberhasilan Pelaksanaan Kegiatan PKM}

Permasalahan-permasalahan yang ada pada mitra adalah pada aspek manajemen produksi dan manajemen pemasaran yang belum optimal, hal tersebut disebabkan oleh pengusaha dalam pengambilan keputusan masih bersifat irasional, yaitu: berdasarkan coba-coba, yang mengakibatkan penilaian rencana bisnis dan evaluasi bisnis mitra tidak objektif, tidak mempunyai target yang jelas dan terukur, serta tidak efektif dan efisien yang berdampak kepada tidak berkembangnya usaha bisnis. Pada aspek produksi permasalahan dalam manajemen produksi mengakibatkan turunnya tingkat pertumbuhan pelanggan disebabkan oleh permasalahan-permasalahan pada faktor-faktor produksi, seperti seringnya terjadi permasalahan pada karyawan, pada mesin-mesin yang tidak terawat ataupun rusak maupun sudah usang, pada bahan baku yang kurang baik, ukuran-ukuran mutu produk yang diabaikan, dan standar operasional prosedur yang tidak dijalankan yang menyebabkan mutu kualitas produk percetakan menurun.

Penilaian kinerja yang irasional atas karyawan dan faktor produksi lainnya. Dengan tidak pahamnya mitra mendeteksi secara dini adanya gap ataupun indeks penurunan pada kinerja manajemen bisnis dan kondisi tersebut dibiarkan terus menerus, dengan jangka waktu yang cukup lama menyebabkan menurunnya kinerja produktivitas pada faktor-faktor produksi, yang berdampak kepada turunnya tingkat pendapatan dan daya saing produk.

Sedangkan permasalahan pada manajemen pemasaran, yang mengakibatkan turunnya tingkat pertumbuhan penjualan usaha disebabkan oleh semakin menurunnya volume penjualan dari waktu ke waktu, hal ini disebabkan oleh strategi promosi yang tidak tepat dan efektif serta target wilayah pemasaran yang tidak potensial, harga dan produk.

Dengan menilai secara rasional indeks kinerja pemasaran secara periodic, maka manajemen dapat mengetahui dan menetapkan prioritas pengambilan keputusan perbaikan bisnis plan dalam rangka pengembangan bisnis usahanya dari aspek target penjualan (produk, promosi, harga dan wilayah pemasaran).

Solusi yang dilakukan kepada mitra adalah pelatihan pengambilan keputusan bisnis plan pengembangan usaha berbantuan komputer. Pengambilan keputusan rasional maksudnya disini adalah perencanaan dan pengembangan bisnis dengan data kualitatif maupun kuantitatif (by data), bukan sebaliknya yang 
biasa dilakukan, yaitu coba-coba, maupun secara intuisi yang mengandalkan kepada preseden atau pengalaman diri sendiri maupun feeling saja.

Pada kegiatan ini mitra diharapkan mendapatkan: a) Khalayak sasaran/mitra dapat membuat bisnis plan pengembangan usaha secara rasional dalam upaya pengembangan bisnis. b) Khalayak sasaran/mitra dapat mengumpulkan data yang dibutuhkan perusahaan, mengolah, menyajikan dan menganalisa data sebagai dasar pengambilan keputusan bisnis plan dalam upaya pengembangan usaha. dan c) Khalayak sasaran/mitra dapat menerapkan bisnis plan pengembangan usaha berbatuan komputer sebagai alat penilaian dan pengambilan keputusan bisnis plan secara efektif dan efisien.

Alat pengumpul data dengan menggunakan checksheet, sedangkan metode pengumpulan data diperoleh baik secara primer: observasi, kuesioner, dan interview, maupun sekunder, yakni data produksi dan penjualan selama 2 minggu, dengan berbantuan komputer program microsoft office excel minimal tahun 2017. Adapun tahapannya seperti penjelasan pada bab metode pelaksanaan pada syb bab 2.1

Metode pendekatan dan penyelesaian yang dilakukan adalah dengan melaksanakan upaya pemberian solusi yang dilakukan dengan metode, yaitu: a. Dikusi terarah (Focused Group Discussion-FGD) untuk memberikan pemahaman kepada mitra tentang orientasi solusi yang diberikan. dan b. Pelatihan: kegiatan pembelajaran untuk meningkatan pengetahuan, pemahaman, dan keterampilan pemanfaatan descriptive statistic dan tabel menggunakan program excel sebagai alat manajemen dalam rangka penilaian untuk pengambilan keputusan rasional pada bisnis plan

Jangka waktu kegiatan pelaksanan selama 6 bulan, selama 6 bulan tersebut termasuk masa pelatihan, yaitu pelaksanan pembelajaran, pembinaan, pendampingan, pembimbingan maupun praktek, evaluasi dan review hingga mitra dapat mengumpulkan, mengolah, dan membuat penyajian data baik secara tabel dan descriptive statistic pada program excel minimal tahun 2007 secara mandiri sebagai dasar pengambilan keputusan bisnis plan pengembangan usaha yang berdampak kepada peningkatan pendapatan bisnis dan daya saing produk).

Pada fase pelaksanaan mitra telah berpartisipasi dengan baik pada kegiatan dengan rinci sebagai berikut:

a. Menjadi peserta pelatihan: menerima teori, konsep, dan panduan,diskusi, tanya-jawab, pengajaran, pembimbingan dan praktek selama mengikuti kegiatan Program Kemitraan Masyarakat dengan baik.

b. Mitra membuat bisnis plan pengembangan usaha dengan pendampingan pengabdi dengan baik.

c. Mitra telah menerapkan bisnis plan pengembangan usaha yang telah dibuat mitra bersama pengabdi sebagai upaya peningkatan penjualan dan berdampak pada peningkatan pendapatan bisnis mitra.

d. Mitra belum dapat membuat bisnis plan pengembangan usaha secara mandiri.

e. Mitra belum dapat menerapkan bisnis plan pengembangan usaha yang telah dibuat sebagai upaya peningkatan penjualan dan berdampak pada peningkatan pendapatan bisnisnya.

Pada fase pelaksanan, pengabdi telah melakukan pelatihan, bimbingan dan pembelajaran dilaksanakan oleh pengabdi bersama kedua mitra di Yayasan SufainyRava, yang beralamat di Jalan Nurul Huda No.72 RT.002/ RW.04, Kelurahan Cempaka Putih, Kecamatan Ciputat, Tangerang Selatan, Banten. Sedangkan pelaksanaan pembuatan bisnis plan/praktek dilaksanakan di CV. Eka Mulia Jaya Production.

\section{Hasil Kegiatan Pemberian Materi Pelatihan Kegiatan PKM Berdasarkan Data Mitra}

Pada tanggal 4 Agustus - 5 Agustus 2018 pada jam 8.00 s. d 16.00 WIB telah dilaksanakan kegiatan Pelatihan PKM 2018 "Praktek Membuat Bisnis Plan Pengembangan Usaha secara Rasional dari Data Selama 2 Minggu Mulai Tanggal 23 Juli s.d. 2 Agustus 2018", hasil kegiatan pemberian materi pelatihan kegiatan PKM dengan judul "Pelatihan Pengambilan Keputusan Bisnis Plan Pengembangan Usaha Berbantuan Komputer 
Bagi Percetakan Skala Kecil di Tangerang Selatan", dari data selama 2 Minggu mulai tanggal 23 Juli s.d. 2 Agustus 2018.

Alat pengumpul data pada praktek 23 Juli s.d. 2 Agustus 2018 dengan menggunakan checksheet, sedangkan metode pengumpulan data diperoleh baik secara primer: observasi, kuesioner, dan interview, maupun sekunder, yakni data produksi dan penjualan selama 2 minggu di CV Eka Mulia Production, dengan berbantuan komputer program microsoft office excel minimal tahun 2017. Adapun data bagian produksi hasilnya adalah sebagai berikut:

Tabel 3.1

BISNIS PLAN BAGIAN PRODUKSI CV. EMJ PRODUCTION DARI TANGGAL 23 JULI S.D. 02 AGUSTUS 2018

\begin{tabular}{|c|c|c|c|}
\hline WHO & WHEN & $\begin{array}{c}\text { Jumlah } \\
\text { Produk } \\
\text { yang } \\
\text { diobser } \\
\text { vasi }\end{array}$ & $\begin{array}{c}\text { Quality } \\
\text { Control } \\
\text { Produk } \\
\text { Error } \\
\text { (defect } \\
\text { produk) }\end{array}$ \\
\hline \multirow[t]{12}{*}{ Karyalita } & $\begin{array}{c}\text { Minggu } \\
\text { Ke-1 }\end{array}$ & 426 & \\
\hline & 23-Jul-18 & 80 & 5 \\
\hline & 24-Jul-18 & 100 & 4 \\
\hline & 25-Jul-18 & 75 & 3 \\
\hline & 26-Jul-18 & 85 & 2 \\
\hline & 27-Jul-18 & 86 & 4 \\
\hline & $\begin{array}{c}\text { Minggu } \\
\text { Ke-2 }\end{array}$ & 427 & \\
\hline & 28-Jul-18 & 86 & 5 \\
\hline & 30-Jul-18 & 85 & 3 \\
\hline & 31-Jul-18 & 86 & 3 \\
\hline & 01-Agt-18 & 85 & 2 \\
\hline & 02-Agt-18 & 85 & 3 \\
\hline \multirow[t]{6}{*}{$\begin{array}{c}\text { Bagus } \\
\text { Prasetyo }\end{array}$} & $\begin{array}{c}\text { Minggu } \\
\text { Ke-1 }\end{array}$ & 414 & \\
\hline & 23-Jul-18 & 75 & 3 \\
\hline & 24-Jul-18 & 85 & 5 \\
\hline & 25-Jul-18 & 84 & 3 \\
\hline & 26-Jul-18 & 80 & 2 \\
\hline & 27-Jul-18 & 90 & 3 \\
\hline
\end{tabular}

\begin{tabular}{|c|c|c|c|}
\hline WHO & WHEN & $\begin{array}{c}\text { Jumlah } \\
\text { Produk } \\
\text { yang } \\
\text { diobser } \\
\text { vasi }\end{array}$ & $\begin{array}{c}\text { Quality } \\
\text { Control } \\
\text { Produk } \\
\text { Error } \\
\text { (defect } \\
\text { produk) }\end{array}$ \\
\hline & $\begin{array}{c}\text { Minggu } \\
\text { Ke-2 }\end{array}$ & $\mathbf{4 2 5}$ & \\
\hline & 28-Jul-18 & 85 & 5 \\
\hline & 30-Jul-18 & 85 & 5 \\
\hline & 31-Jul-18 & 85 & 4 \\
\hline & 01-Agt-18 & 85 & 3 \\
\hline & 02-Agt-18 & 85 & 5 \\
\hline
\end{tabular}

(Sumber: sekunder diolah, 2018)

Berdasarkan data bagian produksi dari tanggal 23 Juli s.d. 02 Agustus 2018 didapat data descriptive statistic dan gambar sebagai alat manajemen dalam rangka penilaian untuk pengambilan keputusan rasional pada bisnis plan tersebut diatas, yakni:

Tabel 3.2

\begin{tabular}{|c|c|}
\hline \multicolumn{2}{|c|}{$\begin{array}{c}\text { Standar Produksi Data } 23 \text { Juli s.d. } 2 \text { Agustus } 2018 \\
\text { di CV. Eka Mulia Production (EMJ) }\end{array}$} \\
\hline Mean & 85,2 \\
\hline Standard Error & 4,188078318 \\
\hline Median & 85 \\
\hline Mode & $\# \mathrm{~N} / \mathrm{A}$ \\
\hline Standard Deviation & 9,364827815 \\
\hline Sample Variance & 87,7 \\
\hline Kurtosis & 1,675622685 \\
\hline Skewness & 1,035193915 \\
\hline Range & 25 \\
\hline Minimum & 75 \\
\hline Maximum & 100 \\
\hline Sum & 426 \\
\hline Count & 5 \\
\hline Confidence Level(95,0\%) & 11,62796955 \\
\hline
\end{tabular}

(Sumber : sekunder diolah, 2018) 
Berdasarkan data bagian produksi dari tanggal 23 Juli s.d. 02 Agustus 2018 dapat ditarik kesimpulan dari data descriptive statistic, berupa standar produk yang diobservasi, yaitu sebesar nilai mean/median, yakni 85, dengan standar error (SE) sebesar $85 \pm 4$, artinya range standar bawah-atas (81-89) diluar dari range ini adalah dibawah rata-rata yang merupakan gap dan diatas rata-rata.

Sedangkan untuk data UD. Alief Jaya Finishing dilaksanakan pada tanggal 18 Agustus - 19 Agustus 2018 pada jam 8.00 s. d 16.00 WIB, telah dilaksanakan kegiatan Pelatihan PKM 2018 "Praktek Membuat Bisnis Plan Pengembangan Usaha secara Rasional dari Data Selama 2 Minggu Mulai Tanggal 6 Agustus s.d. 15 Agustus 2018", hasil kegiatan pemberian materi pelatihan kegiatan PKM dengan judul "Pelatihan Pengambilan Keputusan Bisnis Plan Pengembangan Usaha Berbantuan Komputer Bagi Percetakan Skala Kecil di Tangerang Selatan", dari data selama 2 Minggu mulai tanggal 6 Agustus s.d. 15 Agustus 2018.

Alat pengumpul data pada praktek 6 Agustus s.d. 15 Agustus 2018 dengan menggunakan checksheet, sedangkan metode pengumpulan data diperoleh baik secara primer: observasi, kuesioner, dan interview, maupun sekunder, yakni data produksi dan penjualan selama 2 minggu di UD. Alief Jaya Finishing, dengan berbantuan komputer program microsoft office excel minimal tahun 2017. Adapun data bagian produksi hasilnya adalah sebagai berikut:

Tabel 3.2

\begin{tabular}{|c|c|c|c|}
\hline WHO & WHEN & $\begin{array}{c}\text { Jumlah } \\
\text { Produk } \\
\text { yang } \\
\text { diobservasi }\end{array}$ & $\begin{array}{c}\text { Quality } \\
\text { Control } \\
\text { Produk } \\
\text { Error } \\
\text { (defect } \\
\text { produk) }\end{array}$ \\
\hline & 10 -Agt-18 & 85 & 4 \\
\hline & \begin{tabular}{|c|} 
Minggu Ke- \\
$\mathbf{2}$ \\
\end{tabular} & 485 & \\
\hline & 13-Agt-18 & 110 & 7 \\
\hline & 14-Agt-18 & 120 & 6 \\
\hline & 15-Agt-18 & 90 & 9 \\
\hline & 16-Agt-18 & 85 & 10 \\
\hline & 17-Agt-18 & 80 & 3 \\
\hline \multirow[t]{12}{*}{ Heru } & \begin{tabular}{|c|}
$\begin{array}{c}\text { Minggu Ke- } \\
1\end{array}$ \\
\end{tabular} & 545 & \\
\hline & 06-Agt-18 & 100 & 7 \\
\hline & 07-Agt-18 & 125 & 8 \\
\hline & 08-Agt-18 & 110 & 8 \\
\hline & 09-Agt-18 & 120 & 9 \\
\hline & 10-Agt-18 & 90 & 8 \\
\hline & \begin{tabular}{|c|} 
Minggu Ke- \\
2
\end{tabular} & 510 & \\
\hline & 13-Agt-18 & 90 & 8 \\
\hline & 14-Agt-18 & 80 & 8 \\
\hline & 15-Agt-18 & 110 & 6 \\
\hline & 16-Agt-18 & 110 & 9 \\
\hline & 17-Agt-18 & 90 & 7 \\
\hline
\end{tabular}

(Sumber: sekunder diolah, 2018)

Berdasarkan data bagian produksi dari tanggal 6 Agustus s.d. 15 Agustus 2018 didapat data descriptive statistic dan gambar sebagai alat manajemen dalam rangka penilaian untuk pengambilan keputusan rasional pada bisnis plan tersebut diatas, yakni:

BISNIS PLAN BAGIAN PRODUKSI UD. ALIEF JAYA FINISHING

DARI TANGGAL 6 AGUSTUS S.D. 15 AGUSTUS 2018

\begin{tabular}{|c|r|r|c|}
\hline WHO & WHEN & $\begin{array}{c}\text { Jumlah } \\
\text { Produk } \\
\text { yang } \\
\text { diobservasi }\end{array}$ & $\begin{array}{c}\text { Quality } \\
\text { Control } \\
\text { Produk } \\
\text { Error } \\
\text { (defect } \\
\text { produk) }\end{array}$ \\
\hline $\begin{array}{c}\text { Eko } \\
\text { Juniarto }\end{array}$ & $\begin{array}{c}\text { Minggu Ke- } \\
\mathbf{1}\end{array}$ & $\mathbf{4 8 0}$ & \\
\hline & 06 -Agt-18 & 100 & 9 \\
\hline & $07-$ Agt-18 & 125 & 9 \\
\hline & 08-Agt-18 & 90 & 3 \\
\hline & 09-Agt-18 & 80 & 2 \\
\hline
\end{tabular}

Tabel 3.3

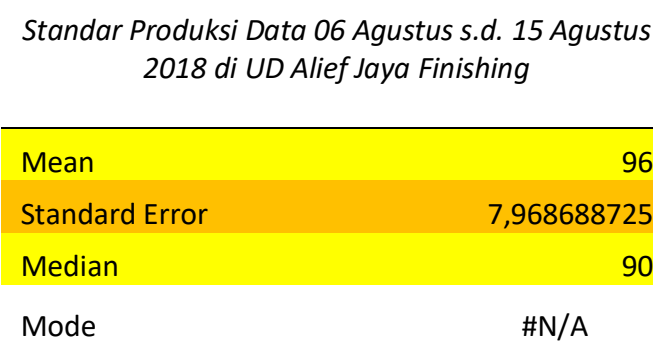

Standard Deviation

17,81852968

Sample Variance 


\begin{tabular}{lr} 
Kurtosis & 1,783743567 \\
Skewness & 1,385357816 \\
Range & 45 \\
Minimum & 80 \\
Maximum & 125 \\
Sum & 480 \\
Count & 5 \\
Confidence Level(95,0\%) & 22,1246268 \\
\hline
\end{tabular}

(Sumber : sekunder diolah, 2018)

Berdasarkan data bagian produksi dari tanggal 6 Agustus s.d. 15 Agustus 2018 dapat ditarik kesimpulan dari data descriptive statistic, berupa standar produk yang diobservasi, yaitu sebesar nilai mean/median, yakni 90, dengan standar error (SE) sebesar 90 \pm 8 , artinya range standar bawah-atas (82-98) diluar dari range ini adalah dibawah rata-rata yang merupakan gap dan diatas rata-rata.

\section{Hasil dan Interprestasi Korelasi Kegiatan Pelatihan}

Berdasarkan hasil interview dan kuesioner yang dilakukan oleh tim pengabdian PKM sebelum pelaksanaan kegiatan pengabdian pada hari Rabu dan Kamis, 30-31 Mei 2018, dan setelah melaksanakan pengabdian pada hari hari Minggu, 28 Oktober 2018, dapat di ilustrasikan dengan tabel di bawah ini.

Tabel 3.4

Hasil Skor

Pengabdian Masyarakat PKM

\begin{tabular}{|c|c|c|}
\hline RESPONDEN & SEBELUM & SESUDAH \\
\hline 1 & 4 & 11 \\
\hline 2 & 5 & 12 \\
\hline 3 & 7 & 13 \\
\hline 4 & 4 & 12 \\
\hline 5 & 5 & 13 \\
\hline 6 & 8 & 14 \\
\hline 7 & 7 & 13 \\
\hline 8 & 4 & 12 \\
\hline 9 & 5 & 12 \\
\hline 10 & 5 & 12 \\
\hline 11 & 4 & 12 \\
\hline
\end{tabular}

\begin{tabular}{|c|c|c|}
12 & 5 & 13 \\
\hline 13 & 8 & 14 \\
\hline 14 & 4 & 13 \\
\hline$\sum$ & 75 & 176 \\
\hline $\mathbf{N}$ & $\mathbf{1 4}$ & \multicolumn{1}{|c}{} \\
\cline { 1 - 2 } & &
\end{tabular}

(sumber: primer, 2018)

Berdasarkan dari hasil tabel 6.44 diatas, maka diolah data dengan menggunakan menggunakan corellation dengan program microsoft excel 2007, menghasilkan hasil sebagai berikut

Tabel 3.5

Hasil Analisis

Corellation

\begin{tabular}{lrr}
\hline & sebelum & sesudah \\
\hline Sebelum & 1 & \\
Sesudah & $\mathbf{0 , 7 9 1 8 9 8}$ & 1 \\
\hline
\end{tabular}

(sumber: primer, diolah 2018)

Untuk dapat menyimpulkan atau menginterpretasikan data analisis tersebut diatas, maka pengabdi berpedoman sesuai tabel.

Tabel 3.6

Pedoman Hasil Korelasi

\begin{tabular}{|c|c|}
\hline $\mathbf{r}$ & Kriteria Hubungan \\
\hline $\mathbf{0}$ & Tidak Ada Korelasi \\
\hline $\mathbf{0}-\mathbf{0 , 5}$ & Korelasi Lemah \\
\hline $\mathbf{0 , 5}-\mathbf{0 , 8}$ & Korelasi Sedang \\
\hline $\mathbf{0 , 8}-\mathbf{1}$ & Korelasi Kuat \\
\hline $\mathbf{1}$ & Korelasi Sempurna \\
\hline
\end{tabular}

(sumber: sekunder, 2018)

Berdasarkan hasil analisis korelasi dan pedoman, sesuai tabel-tabel diatas dapat disimpulkan bahwa dengan mengikuti kegiatan "Pelatihan Pengambilan Keputusan Bisnis 


\begin{abstract}
Plan Pengembangan Usaha Berbantuan Komputer Bagi Percetakan Skala Kecil di Tangerang Selatan", berkorelasi sedang terhadap peningkatan pengetahuan dan keterampilan pengambilan keputusan bisnis plan pengembangan usaha berbantuan komputer dalam rangka meningkatkan daya saing produk dan penjualan bagi mitra.
\end{abstract}

\section{KESIMPULAN DAN SARAN}

\subsection{Kesimpulan}

Kesimpulan akhir dari kegiatan PKM tahun 2018 dengan judul "Pelatihan Pengambilan Keputusan Bisnis Plan Pengembangan Usaha Berbantuan Komputer Bagi Percetakan Skala Kecil di Tangerang Selatan", adalah sebagai berikut:

a) Pada fase pesiapan mitra telah berpartisipasi dengan baik pada kegiatan dengan rinci sebagai berikut:

1. Menyiapkan PC ataupun laptop sebagai media pelatihan pemanfaatan bantuan komputer program descriptive statistic dan penyajian tabel menggunakan program microsoft office excel minimal tahun 2007 sebagai alat bantu pengambilan keputusan bisnis plan dan pengembangan usaha dengan baik

2. Mitra menyiapkan data perusahaan, baik primer maupun sekunder, membantu mengumpulkan data yang dibutuhkan, menyajikan dan menganalisa data produksi dan penjualan selama 2 Minggu selama 4 Bulan (Juli, Agustus, September dan Oktober) Tahun 2018 dengan baik

b) Pada fase pelaksanaan mitra telah berpartisipasi dengan baik pada kegiatan dengan rinci sebagai berikut:

1. Menjadi peserta pelatihan: menerima teori, konsep, dan panduan,diskusi, tanya-jawab, pengajaran, pembimbingan dan praktek selama mengikuti kegiatan Program Kemitraan Masyarakat dengan baik.

2. Mitra membuat bisnis plan pengembangan usaha dengan pendampingan pengabdi dengan baik.

3. Mitra telah menerapkan bisnis plan pengembangan usaha yang telah dibuat mitra bersama pengabdi sebagai upaya peningkatan penjualan dan berdampak pada peningkatan pendapatan bisnis mitra.

4. Mitra dapat membuat bisnis plan pengembangan usaha secara mandiri.

5. Mitra dapat menerapkan bisnis plan pengembangan usaha yang telah dibuat sebagai upaya peningkatan penjualan dan berdampak pada peningkatan pendapatan bisnisnya.

\subsection{Saran}

Saran dari kegiatan pengabdian dengan judul "Pelatihan Pengambilan Keputusan Bisnis Plan Pengembangan Usaha Berbantuan Komputer Bagi Percetakan Skala Kecil di Tangerang Selatan" adalah sebagai berikut:

a) Agar kegiatan yang serupa dilaksanakan kembali pada masa yang akan datang dengan waktu yang lebih lama, lani tempat, dan mitra lainnya.

b) Pencapaian keberhasilan program pengabdian pada tahun 2018 harus dioptimalkan, agar tujuan kegiatan dapat tercapai dengan baik.

c) Pencapaian keberhasilan luaran kegiatan Pengabdian masyarakat berupa luaran wajib maupun luaran tambahan harus dioptimalkan.

\section{DAFTAR PUSTAKA}

Panduan Pelaksanaan Penelitian dan Pengabdian Kepada Masyarakat di Perguruan Tinggi Edisi XI Tahun 2017

Lakip, Politeknik Negeri Media Kreatif, 2015

Widhiasih, Retno Nugoho, dkk. 2015. Proposal $\mathrm{I}_{\mathrm{b}} \mathrm{M}$, Judul : $\mathrm{I}_{\mathrm{b}} \mathrm{M}$ Rumah Disain Teknologi Informasi Kelurahan Harapan Jaya Kecamatan Bekasi Utara Kota Bekasi

http://www.depkop.go.id/content/read/kemenk op-dorong-internasionalisasi-ukm-

melalui-ekspor, Agus Muharam, 2016. diakses 18 Juni 2017

http://download.portalgaruda.org/article.php?article 
